of a slight character, prevailed among the boys in one of the training ships, and there was a slight increase of venereal disease, due to importation from places not under the control of the Contagious Diseases Acts. On the North American and West Indian station yellow fever was extensively epidemic, leading to forty-eight deaths, including that of one assistant-surgeon, who fell a martyr to his devotion to his patients. On the fatal West Coast of Africa great benefit was derived from removing the vessels after a limited period of service, the introduction of this practice reducing the sick-rate 2481 and the death-rate $2 \cdot 6$ per 1000. The total death-rate on that station for the year was $10^{\circ} 4$ per 1000 men, being the lowest on record. On the East Indian station cholera unfortunately prevailed, but only two fatal cases occurred in the squadron.

The medical report of Haslar Hospital by Deputy Inspector R. D. Mason, C.B., shows that, during the year 1869,1348 patients were under treatment in the medical wards; of whom 777 were discharged cured, 310 were invalided, and 60 died. Phthisis, rheumatism, measles, and diseases of the heart were the diseases by which the larger proportion of patients were affected. The surgical report by Deputy Inspector T. Nelson, M.D., and Staff Surgeon J. N. Dick, gives the details of numerous interesting cases, among others of a popliteal aneurism successfully treated by the application of a conical weight. The operations performed were not of especial importance, it being remarkable that no capital operation took place in the hospital during the jear.

The surgical report of the Plymouth Hospital by Deruty Inspector Bernard shows a wider field for practice: 24,48 patients were under treatment; of whom 1886 were cured, 297 invalided, and 72 died. The surgical operations included a successful ligature of the external iliac arterywhich has already appeared in THE LANCET,-amputation of the leg, excision of the elbow, and numerous operations for necrosis. The medical report of the same hospital by Staff Surgeon Irwin shows 930 patients under treatment; of whom 628 were cured, 182 invalided, and 60 died, rheumatism and diseases of the chest being the prevailing maladies.

Deputy Inspector H. J. Domville's report on Melville Hospital, Chatham, shows 1276 admissions; of these 911 were from the Marine division-284 naval officers and seamen,--and the remainder civilians injured in the dockyards of Chatham and Sheerness. Seven of the cases of scald were from the explosion on board the gunboat Thistle in November, 1869; and of these three were fatal.

The Naval Hospital at Haulbowline, under the superintendence of Staff Surgeon J. W. Reid, had but a small number of patients; but sorne of these were of a serious nature, one of them requiring amputation of the arm. The report on the Royal Naval Lunatic Asylum at Yarmouth by Deputy Inspector Macleod is a valuable treatise on lunacy as occurring in the service, to which we shall refer on another occasion. Three essays by officers of the department have been selected for publication with the report. The first is on Heat, by Dr. Alexander Rattray; the second contains notes and statistics relating to boys under training, by Staff Surgeon Wade, which contains much interesting matter; and the third consists of notes of the relative value of vaccination marks, by Assistant-Surgeon E. L. Moss. Altogether the volume is one that is highly creditable to the service, and worthy of the compiler, Dr. Alexander Mackay, the respected head of the statistical branch of the Medical Department.

\section{THE CONTAGIOUS DISEASES ACTS.}

Ar a special meeting of the Gloucestershire Medical and Surgical Association, called to consider the Report of the Royal Commission on the Contagious Diseases Acts, the following resolution and amendment were discussed :-

Resolution proposed by Dr. Washbourne, Gloucester; seconded by Dr. Paine, Stroud :-" That, in the opinion of this Association, the Report of the Royal Commission upon the administration and operation of the Contagious Diseases Acts conclusively proves that in all localities in which the provisions of the Acts have been enforced, great advantages, both moral and physical, have been the result. This
Assuciation therefore believes that the extension of the provisions of the Acts to all sea and inland ports of the United Kingdom would be productive of similar benefitnamely, a marked and progressive diminution both of prostitution and disease."

Amendment proposed by Dr. Morley Rooke, Cheltenham; seconded by Dr. Davey, Northwoods, near Bristol :- "That, in the opinion of this Association, the Report of the Royal Commissioners upon the administration and operation of the Contagious Diseases Acts tends to show that, whilst some physical advantages may have resulted from these Acts, the Commissioners have very grave doubts as to their moral effects and bearings; and, in the face of recommendations by the Commissioners for such amendments of these Acts as would do away with the principal objections of their opponents, it is highly inopportune for this Association to urge an extension of these Acts in an unmodified form to other parts of the kingdom."

The attendance at the meeting was small, the number of members present being sixteen. Many gentlemen who had expressed their intention of attending the meeting were prevented from doing so by professional engagements at the last moment. Of those present, seven voted in favour of the resolution, and eight in support of the amendment.

At a meeting of the Salisbury Medical Society, held on the 1st inst., the following resolution, proposed by Dr. Young, and seconded by Dr. Good, was passed unanimously:"That, in the opinion of this meeting, it is desirable that the Salisbury Medical Society should petition Parliament against the repeal of the Contagious Diseases Acts."

\section{Courespondence.}

\section{"Audi alteram partem." \\ MEDICAL EDUCATION AT CAMBRIDGE. To the Editor of THE LANCET.}

SrR,-A notice in last week's LANCET bas drawn attention to some remarks made by me on a proposal to admit attendance on lectures on experimental physies into the curriculum of medical study at the University of Cambridge. An imperfect report of these remarks, which appeared in the daily newspapers, has led to a misapprehension which I should be glad to correct. The opinion I did express was substantially the same as that of my courteous critic in T'HE LANCET. I hold that a knowledge of experimental physics is of very high importance to medical students. What I objected to was only that the time occupied in their study, together with such subjects as botany and comparative anatomy, should be reckoned as part of the minimum period prescribed for medical study. For ordinary students the University of Cambridge prescribes five years of medical study; for honour students, a minimum of four years. I am of opinion that a period of four years is in no case more than sufficient to devote exclusively to medical studies, and that it should not be curtailed by giving up a part of it to other subjects, which, however important, are not strictly medical. The proposed new regulation would have allowed of this.

$$
\text { Faithfully gours, }
$$

Cambridge, November, 1871. G. E. PAGET, M.D.

\section{THE DEGREE OF M.D.}

To the Editor of 'THe LaNomT.

Sin,-The leading article in your impression of the 18th inst., on the degree of M.D., appears at an opportune time.

I, in common with many other graduates in Arts and Medicine, think a great hardship is imposed on qualified practitioners who are desirous of improving their professional status, by the fact of their being precluded from graduating in medicine because they, from no fault of their own, did not matriculate in some university, or fix their residence in a university town at the outset of their medical studies; as it frequently happens that a variety of reasons, 
pecuniary and others, prevent men from taking these steps at the proper time.

The subject has suggested a plan to me which, if adopted by the universities, would enable such men as I have mentioned to obtain an honourable degree. This plan is-that the several universities should make such changes in their regulations as to allow legally qualified men to pass two fairly testing examinations in arts, giving an interval of a year between each, after which, without residence, they should be allowed to become candidates for the examination for their degree in medicine. This would not make such a degree too easily obtainable, or of slight value, and at the same time would place its attainment within the reach of educated men, and would leave no excuse for the continuation of the scandalous practice of importing purchased foreign degrees.

The languishing university of St. Andrews might be turned into good account in this way. That university, which at present offers no inducement to men to reside there, might with advantage be allowed to examine candidates and grant degrees in medicine in accordance with the regulations of the Scottish Universities Commissioners, minus the requirement of two years' residence.

I am, Sir, yours obediently. Bristol, Nov. 20th, 1871 . Sidnex Herbert Carter, B.A., M.B. T.C.D.

\section{THE TNDIAN MEDICAL SERVICE. \\ To the Editor of THE LANCET.}

SIR,-It is not long since you advocated the cause of the unfortunate candidates for the Indian Medical Service in the columns of THE LANCET, and represented to the authorities and the public the great annoyance and considerable loss of time and money caused by the repeated and indefinite postponement of the examination for the Service. You then pointed out that this policy was a source of great hardship to those candidates who had undertaken costly journeys to this country, sacrificing social advantages and giving up respectable positions in the uncovenanted service for the purpose of obtaining a commission in the medical service of their country. These unhappy candidates have returned home after a residence of nearly two years here, and before they have had time to forget the irreparable losses they sustained, the Indian Government announces that an examination for the medical service will be held in February next. I have just received some extracts from a very influential native journal noticing this decision of the Government, and showing how the authorities have added fuel to the flame and aggravated the injury to the Hindoo candidates.

It is perhaps absurd to think that there is a malicious motive in this policy, but there can be no doubt that these candidates have been greatly wronged, and that the conduct of the authorities has been altogether thoughtless and indifferent, if not unjust. The Indian Mirror proposes "a fair and honourable mode of avenging the injustice that has been done to them accidentally or deliberately," and advises that the disappointed candidates should start for England and appear at the examination in February, and that if they are poor their liberal countrymen ought to extend their belping hands. A subscription-list has been set on foot for the purpose.

Now, Sir, it is possible that these candidates will find the means of coming here in February. But, having regard to the fact that an injustice has been done to them, does it not appear unfair that they should be compelled to return to England for the examination? These candidates used every means in their power to represent the hardships of their case to the authorities. They forwarded in May last a memorial signed by the candidates and endorsed by the professors of the Glasgow and Aberdeen Universities where they had studied, to the Secretary of State for India, to which his Grace the Duke of Argyle sent a very polite and sympathising reply. Failing in this they enlisted the sympathy of an eminent member of Parliament, who moved the subject in the House, to which Mr. Grant Duff made that ever-memorable reply, "I have not the remotest idea" as to when the next examination would take place. It may fairly be asked why Mr. Duff did not telegraph to the Government of India before he gave this very curt answer to Colonel Sykes's question. The Hindoo candidates have been sufferers entirely ethrough the indifference of the Government, and it is to be hoped that enlightened members of the House like Colonel Syles, Sir Edward Colebrooke, Dr. Lyon Playfair, and Mr. Gordon will endeavour to procure for them the privilege of being examined in India, thus avoiding another journey to England.

The regulations for the Indian Medical Service were framed when the colleges in India were in their infancy, and the profession in its cradle. Juring the last few years these colleges have made wonderfully rapid progress, and it has been said by the highest anthorities that they are now equal to any in the United Kingdom. It is unreasonable, therefore, that candidates from India should be compelled to come to England to be examined, and should be required to obtain qualifications in Medicine and Surgery in Great Britain, when they have to practise the healing art in India, and on their own people. You will, I trust, agree with me in the opinion that it is high time the regulations for the Indian Medical Service were revised.

London, Nor, 11th, 1871 I am, Sir, yours, \&c.,

\section{ROYAL FREE HOSPITAL. To the Editor of THE LANCET.}

Sin,-With reference to that portion of the report of your Commissioner which relates to the night-nurses of the above hospital (contained in your number of the 11th), permit me to make the few following remarks, which, as you (in common with us all) have the best interest of the hospital at heart, you will, I am sure, receive with satisfaction, as I assure you you may with safety.

1. Without discussing the ages of the night-nurses, I may say that the Weekly Board have ample testimony that they are, each and every one of them, efficient nurses in every sense of the term, and fully qualified to perform the duties of night-nurses.

2. Each floor has two wards, the doors of which are op. posite to each other; they are generally left open at night, and there never has been, nor is there likely to be, any difficulty in the way of one nurse communicating with another, should need require.

3. Experience shows that there is no difficulty in a nurse being fully cognisant of all the wants of patients in the night at whatever part of the ward such nurse may be.

4. The lady-superintendent invariably goes through the wards once every night, and the nurses have no indication of the time of her visits; in special cases the lady-superintendent visits patients several times during the night.

Wishing you every success in your endeavours to improve the condition of these valuable institutions,

$$
\text { I am, Sir, yours faitbfully, }
$$

JAMES HOPGOOD,

Nov. 22nd̄, 1871. Chairman of General Committee of Hospital.

\section{BIRMINGHAM}

(FROM OUR OWN CORRESPONDENT.)

THe epidemic of small-pox which has been impending over Birmingham for some time has at last declared itself amongst us. The Inspection Committee of the Town Council must at once take steps to provide a temporary hospital for small-pox patients, as the contagious wards of the Queen's Hospital are full, and the authorities of the General Hospital, having already nine cases under treatment, are not anxious to increase the number. It is to be hoped that a medical officer of health will here, as at Wolverhampton, be forthwith appointed, and that prompt action will be taken to ensure the removal and isolation of all cases of the disease without the least delay, and also tho performance of revaccination on a large scale. All the Black Country towns are simultaneously threatened, and in many, as at Oldbury and Bilston, the disease is showing itself in a severe form, and is attacking a great number of persons. At Wolverhampton, however, small-pox has at present found its most numerous victims. There are now 